\title{
Sistem Informasi Akuntansi Laba Rugi Berbasis Microsoft Excel Pada Usaha Mikro Kecil Menengah (UMKM) Lucycake Karawang
}

\author{
Donny Apdian', Yeny Rostiani ${ }^{2}$, Jajang $^{3}$, Fitria Sari ${ }^{4}$ \\ ${ }_{1,2,4}$ Komputerisasi Akuntansi, STMIK Rosma, Karawang \\ ${ }^{3}$ Teknik Informatika, STMIK Rosma, Karawang \\ E-mail: donny@dosen.rosma.ac.id
}

\begin{abstract}
LucyCake is a home industry micro, small and medium enterprise that has been engaged in cake and bakery management since 2015. LucyCake is managed by a housewife as well as a private employee, LucyCake itself is made to order or fresh by order. This study aims to determine the benefits obtained by going through the process of preparing financial statements that focus on the income statement that will help micro, small and medium enterprises (MSMEs) in the process of preparing the correct income statement. This research is a type of descriptive qualitative research, while the data collection method in this study uses interview techniques, observation and literature study according to the research topic. The results of this study are an accounting information system that can support the process of recording financial statements and income statements. With the Microsoft Excel-based profit and loss accounting information system, it is hoped that it can help LucyCake MSMEs in managing the financial reports in the MSMEs.
\end{abstract}

Keywords: Financial Statements, Income Statements, Microsoft Excel, LucyCake

\begin{abstract}
Abstrak
LucyCake merupakan usaha mikro kecil menengah (UMKM) home industry yang bergerak dalam bidang pengelolaan kue dan bakery sejak tahun 2015. LucyCake dikelola oleh seorang ibu rumah tangga sekaligus karyawati swasta, LucyCake sendiri dibuat berdasarkan pesanan atau fresh by order. Penelitian ini bertujuan untuk mengetahui keuntungan yang didapat dengan melalui proses penyusunan laporan keuangan yang berfokus pada laporan laba rugi yang akan membantu para usaha mikro kecil menengah (UMKM) dalam proses penyusunan laporan laba rugi yang benar. Penelitian ini merupakan jenis penelitian kualitatif deskriptif, sedangkan metode pengumpulan data pada penelitian ini menggunakan teknik wawancara, observasi dan studi literatur sesuai dengan topik penelitian. Hasil penelitian ini merupakan sistem informasi akuntansi yang dapat mendukung proses pencatatan laporan keuangan dan laporan laba rugi. Dengan adanya sistem informasi akuntansi laba rugi berbasis Microsoft excel ini diharapkan dapat membantu UMKM LucyCake dalam mengelola laporan keuangan yang ada dalam UMKM tersebut.
\end{abstract}

Kata Kunci: Laporan Keuangan, Laporan Laba Rugi, Microsoft Excel, LucyCake

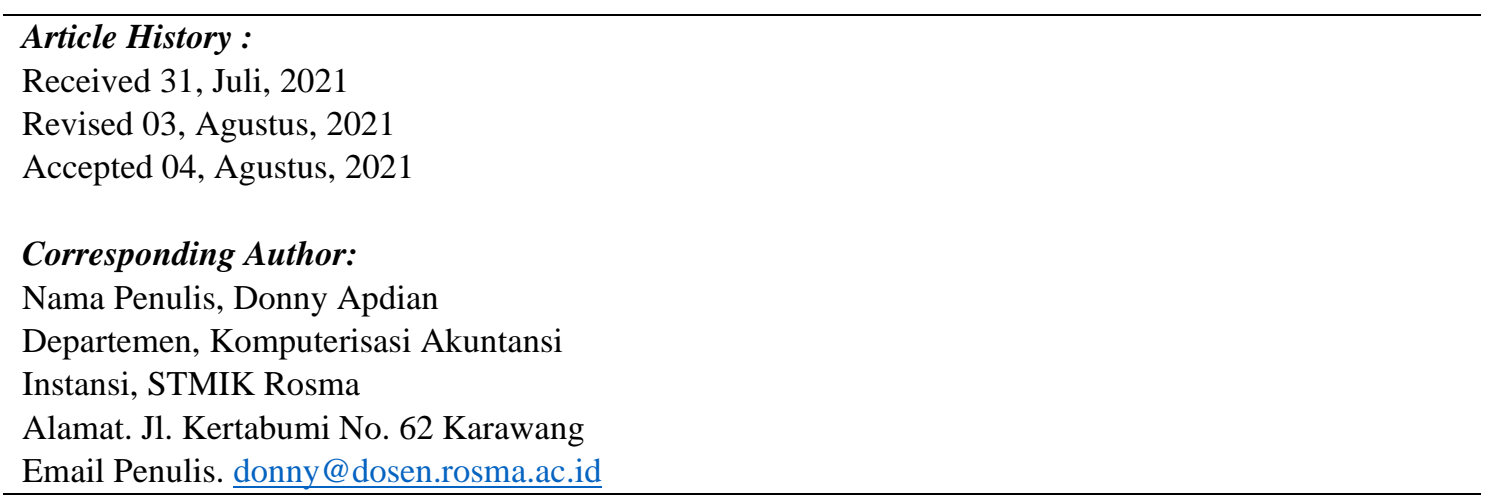




\section{Pendahuluan}

Usaha Mikro Kecil Menengah (UMKM) Lucycake ini merupakan home industry yang bergerak dalam bidang pengelohan kue dan bakery. Lucycake menerapkan sistem by Order dengan adanya pesanan yang diterima maka Lucycake memerlukan bahan baku untuk menjalankan proses produksi. Pembelian bahan baku merupakan faktor utama untuk berlangsungnya kegiatan produksi dan juga pembelian bahan baku ini membantu mengetahui transaksi yang dilakukan oleh lucycake dan membantu proses pembuatan laporan laba rugi.

Laporan laba rugi pada UMKM Lucycake yang belum tersusun dan pencatatan terutama dalam menerima pesanan atau order dan pembelian bahan baku masih dicatat pada buku laporan penjualan. Pencatatan secara manual ini memeliki banyak kelemahan diantaranya seperti akses yang terbatas, rendahnya sistem control dan pengawasan dan juga lebih beresiko tinggi kehilangan data yang penting dan belum tersusunya laporan laba rugi mengakibatkan perusahaan terutama bagi usaha mikro kecil menengah (UMKM) tidak mengetahui kondisi keuangan, pendapatan dan pengeluaran yang dilakukan.

Beberapa peneliti mengungkapkan bahwa microsoft office excel dapat mendukung dalam proses pencatatan keuangan suatu industri sehingga proses bisnis dapat menjadi lebih efektif dan efisien [1][2][3]. Berdasarkan permasalahan yang dihadapi oleh Lucycake dan refernsi penelitian terdahulu, menarik peneliti untuk dapat mengimplementasikan sistem informasi akuntansi yang dapat digunakan untuk pencatatan keuangan sehingga dapat menghasilkan laporan laba rugi yang dapat mendukung dalam proses pengambilan keputusan memerlukan sebuah sistem informasi akuntansi untuk dapat menunjang kegiatan usahanya terutama dalam pembuatan laporan keuangan khususnya pembuatan laporan laba rugi dan sistem pencatatan pesanan atau order dan juga data transaksi pembelian. Agar semua laporan keuangan dan pencatatan sudah menggunakan sistem komputer, dengan adanya sistem tersebut diharapkan mampu memperbaiki permasalahan yang ada.

\section{Tinjauan Pustaka}

\subsection{Sistem Informasi Akuntansi}

Sistem Informasi Akuntansi menurut Romney dan Steinbart (2011) adalah sumber daya manusia, alat dan modal dalam perusahaan yang bertanggung jawab untuk (1) persiapan informasi keuangan dan (2) mengumpulkan dan memproses berbagai transaksi perusahaan [4].

Sistem Informasi Akuntansi adalah kumpulan atau grup dari sub sistem/bagian/komponen apapun baik phisik atau non phisik yang saling berhubungan satu sama dan bekerja sama secara harmonis untuk mengolah data transaksi yang berkaitan dengan masalah keuangan menjadi informasi keuangan [5].

Sedangkan menurut Lilis Puspitawati dan Sri Anggadini Sistem informasi akuntansi dapat pula di definisikan sebagai suatu sistem yang berfungsi untuk mengorganisir formulir, catatan dan laporan yang di koordinasi untuk menghasilkan informasi keuangan yang di butuhkan dalam pembuatan keputusan manajemen dan pimpinan perusahaan dan dapat memudahkan pengelolaan perusahaan [6].

\subsection{Laporan Keuangan}

Laporan keuangan adalah hasil akhir dari proses pencatatan transaksi keuangan suatu perusahaan yang menunjukkan kondisi keuangan suatu perusahaan pada satu periode akuntansi dan merupakan gambaran umum mengenai kinerja suatu perusahaan. Laporan keuangan juga merupakan produk akhir proses akuntansi suatu perusahaan dalam satu periode tertentu di mana informasi di dalamnya merupakan 
hasil pengumpulan dan pengolahan data keuangan, dengan tujuan untuk membantu perusahaan membuat keputusan atau kebijakan yang tepat. Proses penyusunan financial statement menggunakan berbagai sumber data, mulai dari faktur, bon, nota kredit, laporan, bank dan lain sebagainya. Semua data asli transaksi keuangan tersebut digunakan untuk mengisi buku perkiraan dan sebagai bukti keabsahan transaksi [7].

Menurut Lili (2016 : 18-19), secara umum tujuan disusunnya laporan keuangan, yaitu [8]:

a. Memberikan penjelasan tentang kekayaan serta kewajiban suatu kegiatan usaha.

b. Menyajikan informasi yang dapat diandalkan mengenai perubahan kekayaan bersih perusahaan sebagai hasil dari kegiatan usaha.

c. Menyajikan informasi yang dapat diandalkan mengenai perubahan kekayaan bersih perusahaan yang bukan berasal dari kegiatan usaha.

d. Memberikan penjelasan yang mampu membantu pengguna dalam menentukan kemampuan perusahaan dalam memperoleh laba.

e. Menyajikan informasi lain yang relevan dengan keperluan para pemakai laporan keuangan.

\subsection{Microsoft Excel}

Microsoft Excel atau Microsoft Office Excel adalah sebuah program aplikasi lembar kerja yang dibuat dan didistribusikan oleh Microsoft Corporation yang dapat dijalankan pada Microsoft Windows dan Mac OS. Aplikasi ini merupakan bagian dari Microsoft Office System. Aplikasi ini memiliki fitur kalkulasi dan pembuatan grafik yang, dengan menggunakan strategi marketing Microsoft yang agresif, menjadikan Microsoft Excel sebagai salah satu program komputer yang populer digunakan di dalam komputer mikro hingga saat ini. Bahkan, saat ini program ini merupakan program spreadsheet paling banyak digunakan oleh banyak pihak, baik di platform PC berbasis Windows maupun platform Macintosh berbasis Mac OS, semenjak versi 5.0 diterbitkan pada tahun 1993. Sebagai program pengolah angka terpopuler [9].

\subsection{Usaha Mikro, Kecil, dan Menengah (UMKM)}

Menurut Badan Pusat Statistik (BPS) definisi UMKM berdasarkan kuantitas tenaga kerja, yaitu usaha kecil merupakan usaha yang memiliki jumlah tenaga kerja 5 orang sampai dengan 19 orang, sedangkan usaha menengah merupakan usaha yang memiliki jumlah tenaga kerja 20 orang sampai dengan 99 orang [10].

Di Indonesia, definisi UMKM diatur berdasarkan Undang-Undang Republik Indonesia Nomor 20 Tahun 2008 tentang Usaha Mikro, Kecil, dan Menengah. Definisi menurut UU No. 20 Tahun 2008 tersebut adalah [11]:

a. Usaha Mikro adalah usaha produktif milik orang perorangan dan/atau badan usaha perorangan yang memenuhi kriteria Usaha Mikro sebagaimana diatur dalam Undang- Undang ini.

b. Usaha Kecil adalah usaha ekonomi produktif yang berdiri sendiri yang dilakukan oleh orang perorangan atau badan usaha yang bukan merupakan anak perusahaan atau bukan cabang perusahaan yang dimiliki, dikuasai atau menjadi bagian baik langsung maupun tidak langsung dari usaha menengah atau usaha besar yang memenuhi kriteria Usaha Kecil sebagaimana dimaksud dalam Undang-undang.

c. Usaha Menengah adalah usaha ekonomi produktif yang berdiri sendiri yang dilakukan oleh orang perseorangan atau badan usaha yang bukan merupakan anak perusahaan atau cabang perusahaan yang dimiliki, dikuasai, atau menjadi bagian baik langsung maupun tidak langsung dengan Usaha Kecil atau usaha besar dengan jumlah kekayaan bersih atau hasil 
penjualan tahunan sebagaimana diatur dalam Undang-undang.

\section{Metode Penelitian}

Jenis penelitian yang digunakan dalam penelitian ini adalah penelitian kualitatif deskriptif. Penelitian deskriptif kualitatif adalah analisis yang bertujuan untuk menggambarkan segala sesuatu yang sedang berlangsung pada saat penelitian dilaksanakan dan mencoba mengumpulkan data secara teoritis untuk menilai suatu aplikasi nyata sebagai praktek sesungguhnya [12]. Sumber data utama dalam penelitian ini yaitu hasil wawancara dan observasi dengan UMKM LucyCake sebagai informan utama dan kenyataan yang dialami di lapangan, aktivitas pengelolaan laporan keuangan yang ada pada UMKM tersebut.

\section{Hasil dan Pembahasan}

\subsection{Identifikasi Masalah}

Usaha mikro kecil menengah (UMKM) Lucycake pada laporan keuangan belum tersusun, pencatatan order dan data transaksi pembelian yang dilakukan masih dicatat dalam buku laporan penjualan dan belum terkomputerisasi. Segala bentuk pencatatan keuangan yang ada baik pemasukan maupun pengeluaran masih dicatat dalam buku. proses pencatatan hanya transaksi saja tidak termasuk pembuatan jurnal umum dan laporan keuangan. Kekurangan dari sistem yang lama ini adalah resiko tidak mengetahui kondisi keuangan perusahaan dan kehilangan dan kerusakan data yang bersifat penting serta data yang tidak valid akibat pencatatan yang tidak sinkron dan tidak efisien waktu.

\subsection{Flowchart Sistem yang sedang berjalan}

Berikut ini adalah uraian dan gambaran sistem yang sedang berjalan pada usaha mikro kecil menengah (UMKM) LucyCake: a. Pembeli mengajukan order/pesanan kepada pemilik. b. Pemilik menerima pesanan tersebut lalu mencatat nya kedalam buku sebagai penjualan yang dilakukan/melihat jadwal orderan yang lain.

c. Pesanan akan diproses.

d. Pesanan selesai akan dilakukan pengiriman kepada customer.

e. Customer akan melakukan pembayaran melalui Transfer atau COD (Cash On Delivery) dan pesanan diterima oleh customer.

f. Pemilik menerima pembayaran.

g. Pembayaran akan dicatat dibuku yang akan dilakukan untuk memproses laporan keuangan.

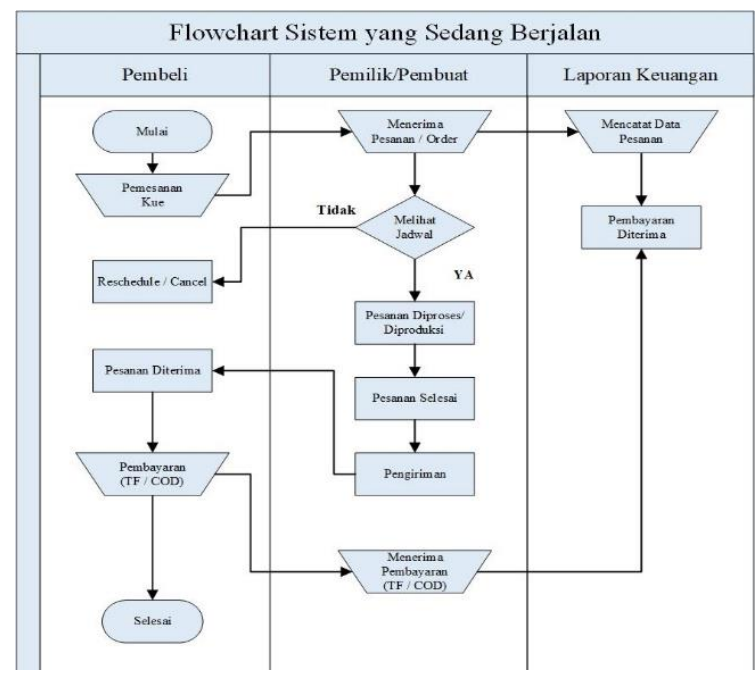

Gambar 1. Flowchart Berjalan Laporan Keuangan Lucycake

\subsection{Analisis Solusi Permasalahan}

Sistem yang akan dibuat untuk Lucycake ini adalah sistem informasi akuntansi yang berupa laporan keuangan berfokus pada laporan laba rugi berbasis Microsoft excel yang dapat membantu mengerjarkan laporan keuangan dan pencatatan yang akan dilakukan. Dimulai dari pencatatan order atau transaksi pembelian sampai pembuatan jurnal penerimaan kas dan pengeluaran kas, dengan adanya data-data tersebut akan membantu proses pengerjaan laporan laba rugi. Dari sistem ini, pemilik bisa melihat data transaksi yang akan dicari sesuai

Jurnal Interkom: Jurnal Publikasi Ilmiah Bidang Teknologi Informasi dan Komunikasi 
dengan kebutuhan. Kelebihan dari sistem ini adalah resiko kehilangan data dan kerusakan data kecil. selain itu dapat mengetahui secara cepat kondisi keuangan serta laporan keuangan menjadi tersusun lebih baik dan waktu mengerjakan efektif dan singkat

\subsection{Flowchart Sistem Usulan}

Berikut ini adalah uraian dan gambaran flowchart sistem yang diusulkan oleh penulis untuk LucyCake:

a. Pembeli mengajukan order/pesanan.

b. Pemilik menerima pesanan tersebut yang dicatat pada penjualan.

c. Pemilik akan melihat jadwal orderan/pesanan kemudian pesanan akan segara diproses.

d. Pesanan selesai dan akan dikirim kepada customer.

e. Customer akan melakukan pembayaran melalui Transfer atau COD (Cash On Delivery) dan pesanan diterima oleh customer.

f. Pemlik menerima pembayaran.

g. Pembayara akan dicatat pada laporan keuangan sebagai penjualan kemudian diproses kedalam laporan laba rugi.

h. Laporan keuangan diketahui oleh pemilik.

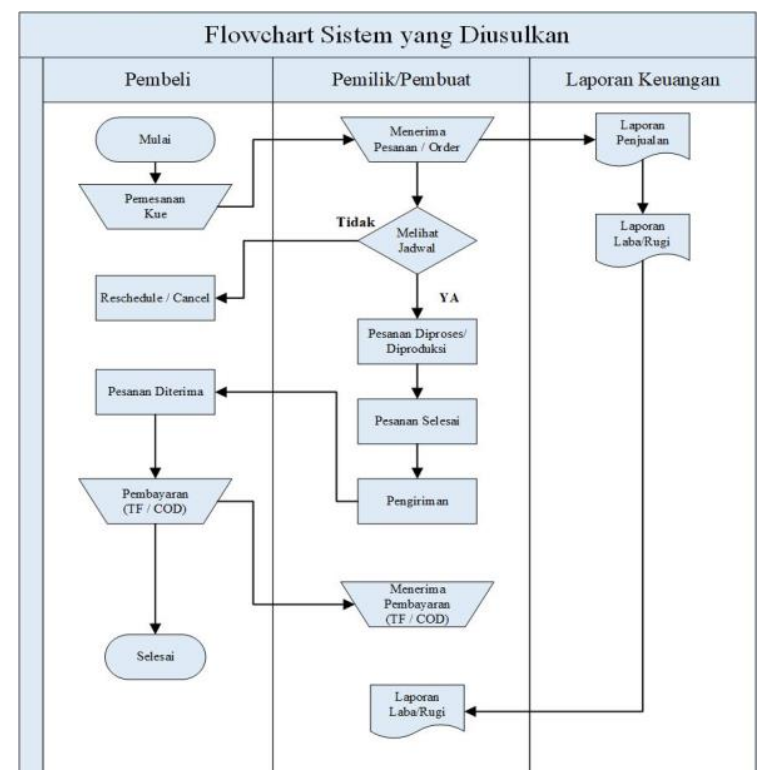

Gambar 2. Flowchart Usulan Laporan Keuangan Lucycake

\subsection{Diagram Konteks}

Diagram konteks adalah gambaran sistem secara keseluruhan, hanya berisi satu proses yang menggambarkan sistem tersebut terhubung dengan entitas eksternal [13]. Diagram konteks dari perancangan sistem dapat dilihat pada gambar sebagai berikut:

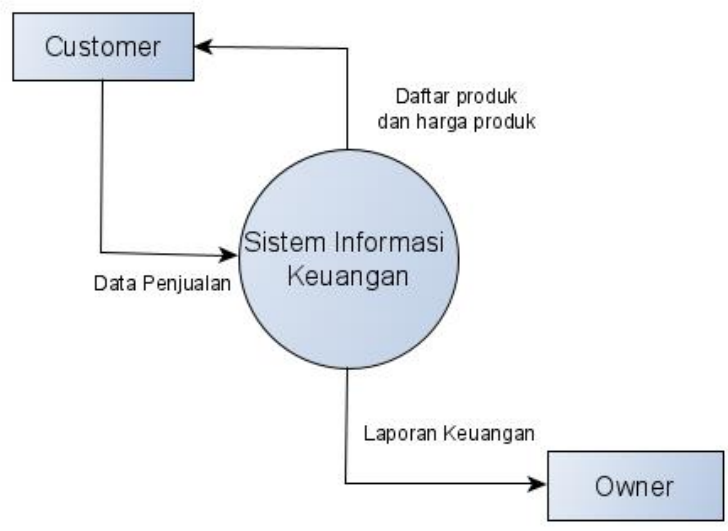

Gambar 3. Diagram Konteks

\subsection{Pembahasan}

Pembuatan laporan keuangan yang berfokus pada laporan laba rugi ini menggunakan Microsoft excel yang akan membantu usaha mikro kecil menengah (UMKM) Lucycake dalam pembuatan laporan laba rugi dan mempermudah pencatatan yang ada.

Hasil dari penelitian ini yang telah dilakukan oleh penulis memiliki dan memberikan suatu solusi yang akan diusulkan kepada pemilik Lucycake yaitu berupa aplikasi untuk laporan laba rugi dan pencatatannya menggunakan Microsoft excel.

Aplikasi laporan laba rugi mengunakan Microsoft excel ini memiliki beberapa jurnal untuk menghasilkan suatu laporan laba rugi diantaranya jurnal penerimaan kas dan pengeluaran kas, jurnal pembelian, jurnal penjualan, neraca saldo dan laporan laba rugi. dapat dilihat pada gambar berikut:

a. Jurnal Penerimaan Kas dan Pengeluaran Kas 
Jurnal penerimaan kas pengeluran kas merupakan jurnal yang mencatat semua transaksi keuangan dan pengeluaran pada Lucycake.

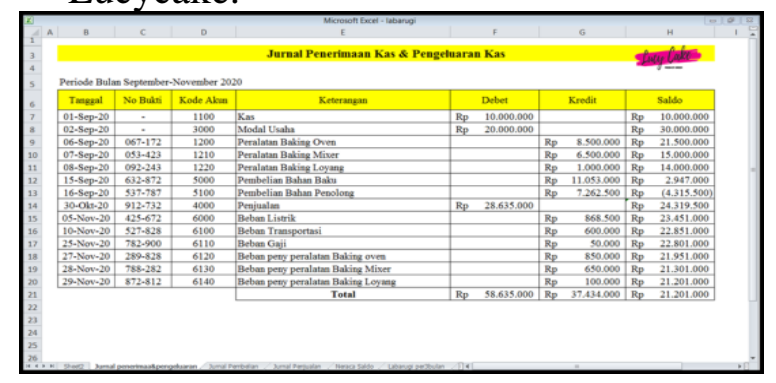

Gambar 4. Tampilan Jurnal Penerimaan Kas dan Pengeluaran Kas

b. Jurnal Pembelian

Jurnal pembeliaan ini merupakan transaksi pembelian yang dilakukan oleh Lucycake.

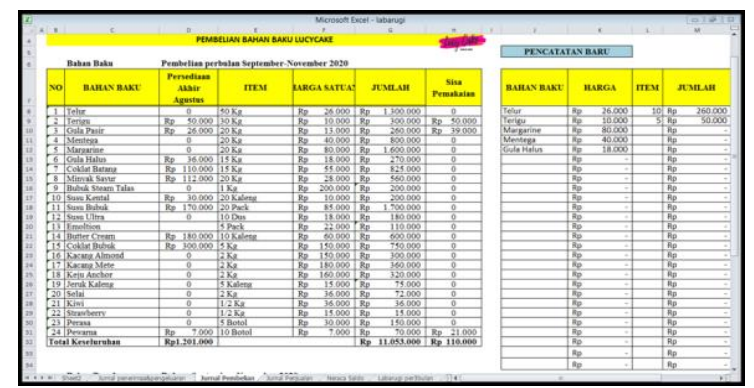

Gambar 5. Tampilan Jurnal Pembelian

c. Jurnal Penjualan

Jurnal penjualan merupakan jurnal yang mencatat pesanan yang diterima dan mengetahui pendapatan pada bulan tertentu yang akan membantu proses pembuatan laporan laba rugi. Pemilik juga sudah bisa melalakukan pencatatan yang akan mempermudah pekerja dengan efesien.

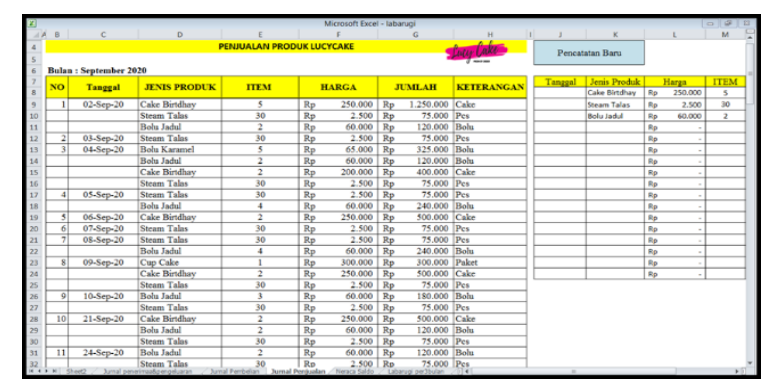

Gambar 6. Tampilan Jurnal Penjualan d. Neraca Saldo

Neraca saldo merupakan komponen penting yang akan membantu proses pembukaan untuk mencatat segala transaksi pada LucyCake dan membantu proses pengerjaan laporan laba rugi.

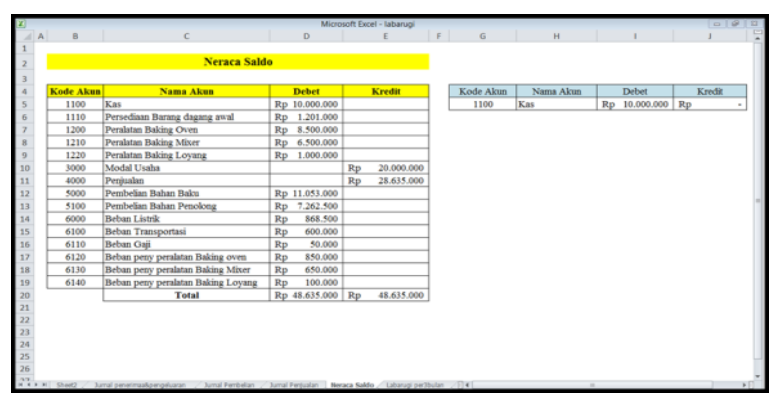

Gambar 7. Tampilan Neraca Saldo

\section{e. Laporan Laba Rugi}

Laporan laba rugi merupakan laporan yang berisi pendapatan dan beban-beban yang dilakukan oleh lucycake yang akan diproses untuk mengetahui laba pada periode tertentu dan juga mengetahui kondisi LucyCake.

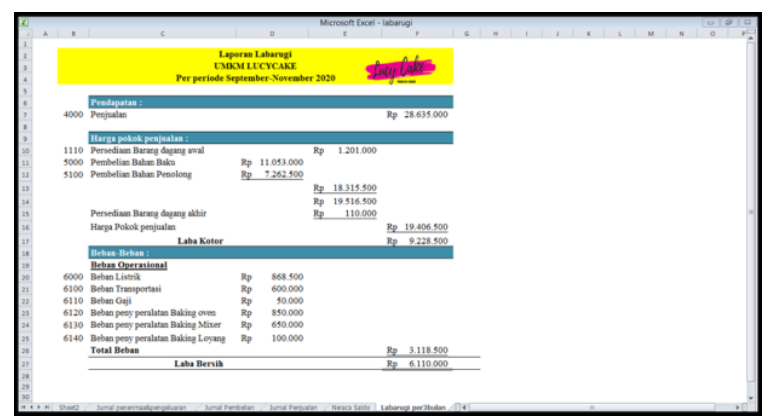

Gambar 8. Laporan Laba Rugi

\section{Daftar Pustaka}

[1] F. Diba and M. Marini, "Penerapan Laporan Keuangan Berbasis Excel pada Bengkel Las Bina Logam," Pros. Semin. Nas. Akunt. III, vol. 3, no. 1, pp. 257-266, 2020.

[2] E. A. Wahyuni, D. Probowulan, and R. Murwanti, "EKSISTENSI PENCATATAN KEUANGAN BERDASARKAN SAK EMKM PADA UMKM DENGAN

Jurnal Interkom: Jurnal Publikasi Ilmiah Bidang Teknologi Informasi dan Komunikasi

Volume 16 Nomor 02 Bulan Juli - Tahun 2021 
APLIKASI MICROSOFT EXCEL,"

Budg. J. Business, Manag. Account., vol. 2, no. 1, 2020.

[3] E. Kania and A. Irawan, "Penyusunan Laporan Keuangan Berdasarkan SAK EMKM Berbantuan Microsoft Excel Pada UMKM Uncal.Co," Indones. Account. Lit. J., vol. 1, no. 2, pp. 338352, 2021.

[4] N. E. Prastika and D. E. Purnomo, "PENGARUH SISTEM

INFORMASI AKUNTANSI

TERHADAP KINERJA

PERUSAHAAN PADA USAHA MIKRO KECIL DAN MENENGAH (UMKM) DI KOTA PEKALONGAN," J. LITBANG, vol. 4, no. 3, 2019.

[5] D. Darwis, F. D. Apriyanti, and E. R. Susanto, "Perancangan Sistem Informasi Akuntansi Pengeluaran Operasional Perusahaan (Study Kasus: PT Sari Segar Husada)," $J$. TEKNOKOMPAK, vol. 13, no. 1, pp. 1-6, 2019.

[6] A. R. Asari, "Perancangan Sistem Informasi Akuntansi Pembelian Pada PT Khomsah Khalifah Dengan Menggunakan Software PHP dan MySQL," @is Best Account. Inf. Syst. Inf. Technol. Bus. Enterp., vol. 3, no. 1, pp. 249-261, 2018, doi: 10.34010/aisthebest.v3i1.1816.

[7] M. Audrilia and A. Budiman, "Perancangan Sistem Informasi Manajemen Bengkel Berbasis Web (Studi Kasus : Bengkel Anugrah)," J. Madani Ilmu Pengetahuan, Teknol. dan Hum., vol. 3, no. 1, pp. 1-12, 2020, doi: 10.33753/madani.v3i1.78.

[8] S. L. Lestari and D. Gustinya, "Implementasi Standar Akuntansi Keuangan Entitas Tanpa Akuntabilitas Publik Dalam
Penyajian Laporan Keuangan Pada PT Aurindo Jaya Perkasa," J. Akunt. dan Bisnis Krisnadwipayana, vol. 6, no. $1, \quad 2019, \quad$ doi: 10.35137/jabk.v6i1.255.

[9] M. I. Siregar, A. Saggaf, M. Hidayat, and S. M. Palembang, "PELATIHAN PEMBUATAN LAPORAN KEUANGAN BERBASIS MICROSOFT EXCEL PADA KERAJINAN SONGKET MAYANG," J. ABDIMAS MANDIRI, vol. 5, no. 1, pp. 51-56, 2021.

[10] M. N. Ilmi and F. Metandi, "Perancangan Sistem Informasi Produksi Dan Penjualan Pada Umkm Bakpia (Studi Kasus Aa Bakery)," Just TI (Jurnal Sains Terap. Teknol. Informasi), vol. 12, no. 1, p. 17, 2020, doi: 10.46964/justti.v12i1.180.

[11] J. E. Pembangunan, F. Ekonomi, and U. S. Ratulangi, "Analisis Pengaruh Modal Dan Biaya Produksi Terhadap Pendapatan Umkm Di Kota Kotamobagu," J. Berk. Ilm. Efisiensi, vol. 19, no. 01, pp. 56-67, 2019.

[12] M. Anggeraini, N. Astuti, and A. Agin, "Upaya Penerapan Sistem Informasi Akuntansi Berbasiskomputer Menggunakan Microsoft Excel Terhadap Efektivitas Pengendalian Internal Sistem Penjualan Kasus Pada Cv . Media Sari Prima," J. Akunt. BISNIS DAN Keuang., vol. 7, no. 1, pp. 37-46, 2020.

[13] M. Abdurahman, "Sistem Informasi Data Pegawai Berbasis Web Pada Kementerian Kelautan Dan Perikanan Kota Ternate," J. Ilm. Ilk. - Ilmu Komput. Inform., vol. 1, no. 2, pp. 7078, 2018, doi: 10.47324/ilkominfo.v1i2.10. 